\title{
Leadership and Gen Z: Motivating Gen Z Workers and Their Impact to the Future
}

\author{
Arthur M. Baldonado \\ Adjunct faculty at Ashford University and University of Phoenix, US
}

*Corresponding Author: Arthur M. Baldonado, Adjunct faculty at Ashford University and University of Phoenix, US

\begin{abstract}
What motivational factors impact Gen Z? Understanding this newest entrant to the workplace is of paramount importance for organizations today. This article explores the motivational needs of Gen $Z$ and their impact in the workplace based on Herzberg's two-factor theory of motivation. The author used a researcher-developed, written survey methodology. The study findings indicated a strong propensity for growth among Gen Z. Both hygiene and motivator factors are important to Gen Z's motivational needs. Managers must be cognizant of Gen Z's motivational needs and traits to lead effectively.
\end{abstract}

Keywords: Gen Z, Motivation, Two-Factor theory

\section{INTRODUCTION}

What motivational factors impact Gen Z? Understanding this newest entrant to the workplace is of paramount importance for organizations today. Generation Z, iGen, Post-Millennial, Gen Tech, Digital Natives, Net Gen, Facebook Generation, and Plurals are some of the descriptors used to identify and label this newest generation. Referred to as Gen $\mathrm{Z}$ in this study, Gen $\mathrm{Z}$ are individuals born between 1995 to 2010 (Bencsik, Horvath-Csikos \& Jubasz, 2016). According to Forbes, Gen Z comprises $25 \%$ of the U.S. population, making them a larger cohort than their previous predecessors (Ryan, 2016). Currently, Gen $Z$ has begun entering the workforce (Kubatova, 2016). According to Shatto \& Erwin (2016), much of the press has been devoted to Millineials, but little has been written about the special characteristics and learning styles of Gen $\mathrm{Z}$.

\section{BACKGROUND}

As Gen $\mathrm{Z}$ employees begin to enter the workplace and become a stronger and larger group in the workplace, managers and executives must develop flexible and varied managerial behaviors to effectively motivate and manage this cohort. Thus, conducting research on generational differences, similarities, and needs are essential if managers are going to be equipped "with the knowledge required to make informed decisions and implement strategies for creating environments that people want to become part of and stay in" (Legault, 2002, p. 4). Failure to address generational issues may cause misunderstandings and miscommunications (Smola \& Sutton, 2002).

Gen $\mathrm{Z}$ has grown up with technology, and the past decades brought the ubiquity of email, YouTube, social networks, tablets, and smart phones and changing the ways Americans interact (Philip \& Garcia, 2013). Social networking sites such as Facebook and Twitter are one of the most commonly used forms of communication for this newest generation (Kick, Contacos-Sawyer \& Thomas, 2015). Futhermore, Gen $\mathrm{Z}$ was born into technology, and the widespread usage of the Internet is a significant factor distinguishing this generation. Studies has shown that $\mathrm{Gen} \mathrm{Z}$ are exposed to social media more than any other activity - Every 60 seconds, 2.5 million pieces of content shared in Facebook, 100,000 tweets sent, and 48 hours of YouTube video created (Shatto, \& Erwin, 2016).

Both the September 11 terrorist attacks and the Great Recession grealty infuenced this newest generation. Research indicates that Gen $\mathrm{Z}$ are practical, intelligent, impatient, agile, and brave and are not afraid to take the lead and challenges. To solve problems, Gen $Z$ try to find solutions on the internet (Bencsik, Horvath-Csikos, \& Jubasz, 2016). Morevoer, Gen Z students learn best by observation and practice, not by reading and listening to PowerPoint presentations as their affinity to 
Google information is remarkable; however, their ability to fully critique the validity of this information may be lacking (Shatto \& Erwin, 2016).

\section{TWO-FACTOR THEORY}

Frederick Herzberg (1968) developed the motivator/hygiene theory or two-factor theory. Herzberg began his research in the mid-1950s by surveying 200 engineers and accountants for framework around their motivators (Wagner \& Hollenbeck, 2001). By combining his findings with other researchers using different frameworks, Herzberg developed a model of motivation on the assumption that factors eliciting job satisfaction and motivation are independent from those producing job dissatisfactions.

The two-factor theory assumes that factors producing job satisfaction (motivators, or intrinsic rewards) differ from those producing job dissatisfaction (hygiene factors, or extrinsic rewards). The motivators are "achievement, recognition for achievement, the work itself, responsibility, and growth or advancement" (Herzberg, 1968, p. 91-92). The hygiene or dissatisfaction-avoidance factors, which are extrinsic to the job, include "company policy and administration, supervision, interpersonal relationships, working conditions, salary, status, and security" (Herzberg, p. 92). Herzberg concluded that removing hygiene factors did not guarantee employee satisfaction, but simply brought peace within an organization and does not motivate employees. Satisfaction is only increased with motivators, suggesting job roles should be redefined to increase recognition, responsibility, achievement, and advancement.

\section{RESEARCH QUeSTIONS AND MeThODOLOGY}

This paper seeks to explore the workplace motivational factors and provide winning strategies in strengthening job satisfaction of Gen Z. The research is spurred by the need for further academic research on Gen Z. In reviewing the existing literature, two articles were located on-line through ProQuest academic database using "Gen Z," "Workplace," and "Motivation" as search terms locators.

The following research questions were used to guide this study of Generation $\mathrm{Z}$ based on Herzberg's two-factor theory model:

1. What motivator factors help motivate Gen $\mathrm{Z}$ employees in the workplace?

2. What hygiene factors help motivate Gen $\mathrm{Z}$ employees in the workplace?

3. What strategies can managers provide to strengthen job satisfaction of Gen $\mathrm{Z}$ employees?

This researcher explored and described the motivational and management needs of Gen $\mathrm{Z}$ members and has selected a qualitative, descriptive research approach to collect the primary data. This study is qualitative and descriptive in nature, as it does not assess causal relationship, but instead, compiles and describes data. Descriptive studies can provide a one-time snapshot or description of a population or a phenomenon at a given point in time (Trochim, 2001). The data was gathered using a researcherdesigned, written questionnaire and was administered to Air Force Recruits at Woodbridge, Virginia. The researcher-designed, written questionnaire was examined by three college professors at North central University for validity and reliability, and a pilot study was conducted and administered to personnel at Hickam Air Force Base for soundness of survey instrument. The survey composed of two sections: A) Demographic sections; and B) Two-factor theory questionnaire. The results of the study are intended to provide a body of knowledge relating to the motivational and management needs of Gen Z. The need for this study is significant and useful for management in helping analyze the motivational and management needs of Gen $\mathrm{Z}$.

\section{SURVEY RESUlT}

Section A responses to demographic information indicate majority of the respondents were male, and the study successfully targeted Gen Z members-all survey participants were Gen Z members (born after 1995). Most of survey respondents were of African American, Hispanic, and Asian descents. In Section B, the researcher sought to explore the importance of the 16-hygiene/motivator factors of Herzberg's two-factor theory of motivation (1968). The following five-point Likert scale were offered to survey respondents: very important, important, moderately important, little importance, and not important. Eleven Gen $\mathrm{Z}$ members participated in the survey. Below depict the results of the survey based on mean, median, and mode. 
Leadership and Gen Z: Motivating Gen Z Workers and Their Impact to the Future

\begin{tabular}{|l|l|l|l|}
\hline \multicolumn{1}{|c|}{ Factors } & \multicolumn{1}{c|}{ mean } & median & mode \\
\hline growth & 1.18 & 1 & 1 \\
\hline achievement & 1.27 & 1 & 1 \\
\hline work itself & 1.27 & 1.5 & 1 \\
\hline responsibility & 1.27 & 1 & 1 \\
\hline advancement & 1.27 & 1 & 1 \\
\hline security & 1.45 & 1 & 1 \\
\hline personal life & 1.45 & 1.5 & 1 \\
\hline relationship w/ subordinates & 1.54 & 1.5 & 2 \\
\hline relationship w/ peers & 1.54 & 1 & 2 \\
\hline relationship w/ supervisor & 1.72 & 1 & 2 \\
\hline salary & 1.9 & 2 & 2 \\
\hline supervision & 1.9 & 1.5 & 2 \\
\hline company policy and administration & 1.9 & 1.5 & 2 \\
\hline work conditions & 2.09 & 2.5 & 2 \\
\hline recognition & 2.27 & 2 & 2 \\
\hline status & 2.63 & 3 & 3 \\
\hline
\end{tabular}

\section{DISCUSSION}

Upon analyzing Gen $\mathrm{Z}$ responses to the survey, it was clear that this cohort had distinct motivation/hygiene needs. Responses to the survey indicated Gen $\mathrm{Z}$ placed great importance to both hygiene and motivator factors. However, a few factors stood out among the others. The 16 hygiene/motivator factors received an average mean of 2.42. Ten hygiene factors were surveyed in this study: security, status, relationship with subordinates, personal life, and relationship with peers, salary,work conditions, relationship with supervisor, supervision, and company policy/administration. Furthermore, six motivator factors were surveyed in the study: achievement, recognition, work itself, responsibility, advancement, and growth.

Survey responses depicted growth as the highest source of motivational factors to Gen $\mathrm{Z}$ participants (mean score of 1.18). Similarly, achievement, work itself, responsibility, and advancement placed among the top tiers in this survey. Conversely, status, recognition, and work conditions rank at the bottom tier in the mean average on this survey. Since hygiene factors are extrinsic to the individual, their absence caused dissatisfaction. However, hygiene factors do not lead to higher levels of motivation (Herzberg, 1968). Herzberg stated that motivator factors, if present, led to feelings of satisfaction and were needed to motivate employees into higher performance because motivator factors result from intrinsic instincts in workers, yielding motivation.

\section{RECOMMENDATION}

The following strategies can help managers strengthen Gen Z's job satisfaction:

- Provide Gen $\mathrm{Z}$ workers with opportunities to grow in their job - Growing in one's career was important to Gen Z. Managers can provide Gen Z with challenging work as their skill and knowledge progressed.

- Use achievement to reward/motivate Gen $\mathrm{Z}$ workers - When Gen $\mathrm{Z}$ achieves at work, managers can motivate Gen $Z$ by using rewards or increased responsibility. For instance, recognition of "employee of the month" award can provide motivation to a Gen Z worker. Managers can customize rewards and incentives to best fit an employee's need (i.e., gift certificates or day off).

- Create working conditions suited for Gen Z - A safe, comfortable working environment mattered to Gen $\mathrm{Z}$ workers. Managers must clearly articulate safety and fun at work to employees. Having a fun and comfortable working environment can greatly motivate Gen $\mathrm{Z}$ cohort.

- Offer increased responsibilities as a reward - Gen Z workers viewed being trusted with responsibility as a good motivator. Managers can offer increased responsibility as a reward for an employee's good performance.

- Use social media as a resource to help motivate Gen Z - Gen Z spends most of their time in social media, and organizations can leverage this platform to their advantage. 
Perhaps the greatest benefit of this study is that it will increase awareness and discussion among managers and business leaders on how to effectively motivate and manage Gen $\mathrm{Z}$ members in the workplace. While other theories of motivation may prove useful in exploring workplace motivational and managerial factors of Gen $\mathrm{Z}$ workers, this researcher was intrigued in the popularity and utility of the two-factor theory among business practitioners. It is recommended that managers and leaders tailor their managerial needs to effectively and better motivate/manage Gen $\mathrm{Z}$ members.

Having a flexible, adaptable approach can help managers better understand and motivate this emerging cohort. Next, managers must understand the basic trait of Gen Z-technology savvy, learn best by doing, and social media generation. Gen $\mathrm{Z}$ members want meaningful/challenging work that let them grow on their jobs. Likewise, Gen $Z$ workers value the importance of balancing their personal and professional lives. Leaders and managers who understand Gen $\mathrm{Z}$ needs of growth and work/life balance will gain the competitive edge of an organization, increase recruitment and retention, and ultimately create a stronger organization.

\section{Limitations AND FUtURE RESEARCH RECOMMENDATION}

Based on their response to the demographic questions, this researcher assumed that the respondents to the survey are, in fact, a member of Gen Z cohort. In addition, this author assumed that participants were answering the survey questions honestly and voluntarily and thereby providing data, which truly reflected the perceptions of Gen $\mathrm{Z}$ cohort.

The main limitation in the methodology was that the study was limited to the perceptions of Gen $\mathrm{Z}$ students at the east coast region of the United States. Some other limitations included - the findings were limited to participants who volunteered and completed the surveys; small sample size; and the instrument used in the study was self-designed questionnaire and its validity may need further examination.

Areas requiring further research include: 1) measuring the difference (if any) in hygiene/motivator factors among Gen $\mathrm{Z}$ workers; 2) determining if results from a repli-cated study using respondents who are actually employed agree or disagree with the finding of this study; 3 ) how motivator and hygiene factors impact Gen $\mathrm{Z}$ employees in the workplace.

\section{CONCLUSION}

Motivating Gen $\mathrm{Z}$ is vitally important in today's highly competitive, global marketplace. This newest generation are techno-savvy, tactile learners, and social media generation. This study started out with the basic question - what motivates Gen $\mathrm{Z}$ workers? Gen $\mathrm{Z}$ is a fascinating generation full of potential and energy. Leaders must understand the basic traits and motivational needs of Gen $\mathrm{Z}$ to effectively lead them to the future.

\section{REFERENCES}

[1] Bencsik, A., Horvath-Csikos, G., \& Jubasz, T. (2016). Y and Z generations at workplaces. Journal of Competitiveness, (8)3, 90-106.

[2] Geck, C. (2006). The generation z connection: Teaching information literacy to the newest net generation. Teacher Librarian, (33)3, 19-23.

[3] Herzberg, F. (1968). One more time: How do you motivate employees? Harvard Business Review, 81(1), 87-96.

[4] Hoffman, T. (2003). Preparing generation z. Retrieved from http://www.lasseigne.com/education/art082503a.pdf

[5] Kick, A. L., Contacos-Sawyer, J., \& Thomas, B. (2015). How generation z's reliance on digital communication can affect future workplace relationships. $C F,(13) 2,214-222$.

[6] Kubatova, J. (2016). Work-related attitudes of czech generation z: International comparison. Central European Business Review, (5)4, 61-70.

[7] Legault, M. (2002). Bringing people together: A study of generational diversity and organziational culture (Doctoral dissertation, Royal Rods Unversity (Canada, 2002). Dissertation Abstract International, 41/02, 443.

[8] Philip, T. M. \& Garcia, A. D. (2013). The importance of still teaching the iGeneration: New technologies and the centrality of pedagogy. Harvard Educational Review, (83)2, 300-401.

[9] Ryan, S. (2016). Get ready for Gen Z. Forbes. Retrieved from https://www.forbes.com/sites/ causeintegration /2016/11/28/ get-ready-for-generation-z/\#317435242204 
[10] Shatto, B. \& Erwin, K. (2016). Moving on from millennials: Preparing for generation z. The Journal of Continuing Education in Nursing, (47)6, 253-254.

[11] Smola, K. W., \& Sutton, C. D. (2002). Generational differences: Revisiting genration work values for the new millenium. Journal of Organziational Behavior, 23, 363-382.

[12] Trochim, W. (2001). The research methods knowledge base (2nd ed). Cincinatti, OH: Atomic Dog Publising.

[13] Van Oord, L. \& Corn, K. (2013). Fostering criticality for the iGeneration. International Schools Journal, (32) 2, 51-56.

[14] Wagner, J. A. \& Hollenbeck, J. R. (2001). Organizational behavoir: Securing a competitive advantage. Forth Worth, TX: Harrcourt College Publishers.

\section{AUTHORS BIOGRAPHY}

Dr. Baldonado is an adjunct faculty at Ashford University and University of Phoenix. His areas of expertise include human resources, work motivation and diversity, business administration, and management. Dr. Baldonado has over 20 years of human resources experience and has published in his field.

Citation: Arthur M. Baldonado. "Leadership and Gen Z: Motivating Gen Z Workers and Their Impact to the Future." International Journal of Managerial Studies and Research (IJMSR), vol 6, no. 1, 2018, pp. 56-60. doi:http://dx.doi.org/10.20431/2349-0349.0601001.

Copyright: () 2018 Authors. This is an open-access article distributed under the terms of the Creative Commons Attribution License, which permits unrestricted use, distribution, and reproduction in any medium, provided the original author and source are credited. 